$\mathrm{O}$ autor investiga as modificaçōes na prática analítica e suas consequêencias na reformulação da teoria em Freud e Lacan e articula essas modificaçōes com o contexto da pósmodernidade. A possibilidade de o sujeito produzir transferência, entendida como suposição de saber ao Outro, estaria modificada na pós-modernidade. $O$ autor mostra que o período do ensino de Lacan chamado de "segunda clínica" caracteriza-se pelo abandono da comunicação de saber como agente do tratamento e propóe que esse procedimento possibilita à psicanálise atuar nas características do sujeito pós-moderno, bem como rompe com os cânones anteriores da interpretaçào analitica.

Psicanálise; inconsciente; materialidade; sujeito; pós-moderno; letra

\section{IN LACAN'S "SECOND} CLINIC" THE WORDS DON'T GO TO THE OTHER

The author searches the modifications in analytical practice and its consequences in the restatement of Freud and Lacan's theory, and articulates these modifications with the post-modernity context. The possibility to produce transference as a suposition of knowledge to the Other would be changed in postmodernity in its relation with the knowledge. The author shows that Lacan's reaching period called as "second clinic" characterizes itself by the abandonment of the knowledge communication as the agent of treatment and points out that this procedure gives the possibility to actuate in the post-modern subject's characteristics as well as it tears with the previous canons of the analytical interpretation.

Psychoanalysis; unconscious; materiality; subject; post-modernity; letter

\section{NA SEGUNDA \\ CLÍNICA DE LACAN \\ A PALAVRA NÃO SE \\ DIRIGE AO OUTRO}

\section{MODIFICAÇÕES DA PRÁTICA ANALÍTICA E TRANSFERÊNCIA COMO SUPOSIÇÃO DE SABER}

$\Leftrightarrow$

clínica impõe a reflexão sobre a existência de modificações no inconsciente, pois, como no caso da histeria, os sintomas podem mudar. Demonstrando também mudanças na subjetividade, pode-se apontar o gosto dos jovens pelos "esportes radicais", tatuagens, piercing, além de uma prevalência maior de casos de anorexia, e também recurso comum ao sexofone, e ao sexo pela internet.

Essas modificações da subjetividade podem ser entendidas pelo fato de o inconsciente estar estruturado como linguagem: como a linguagem muda, o inconsciente também muda. Assim como muda o sujeito, devido a ele decorrer da linguagem. Da mesma maneira, a prática e a teoria da

Médico, psiquiatra, psicanalista, diretor-geral da EBP-SP. Autor de Psicanálise lacaniana, 2000. 
psicanálise também estão em constante modificação. Freud (1920, p. 17), na introdução de "Além do princípio do prazer", relata a evolução da prática da psicanálise até então, situando a origem da cura psicanalítica nos relatos feitos nos "Estudos sobre a histeria", em que sua causa aparecia correlacionada à comunicação feita ao paciente reveladora do seu desejo (inconsciente). Essa interpretação seria o instrumento pelo qual o analista comunicaria ao paciente a verdade sobre seu (desejo) inconsciente, que seria deduzida das representações mobilizadas na associação livre (1895, p. 43). Poderia indicar-se como paradigma desse momento a ação de "tornar consciente o inconsciente".

Em um segundo momento, iniciado com o relato do caso Dora, Freud, ao incluir a transferência na direção do tratamento, deslocou a interpretação do desejo inconsciente para o repetido na transferência, propondo "privilegiar a recordação em detrimento da repetição”.

Um terceiro momento, situado a partir de "Além do princípio do prazer", testemunha a virada ética de Freud, em que o psíquico deixou de ser explicado com a analogia da homeostase. produzida pela evitação de desprazer, para admitir que o sujeito busca um bem que não se identifica com o seu bem-estar. Como conseqüência desta evolução na prática da psicanálise, Freud em "Construções em análise" sugere que a cura se daria pela presentificação de traços mnêmicos, produzindo novas possibilidades de ligação entre eles. Ao questionar a impossibilidade de existir a recuperação de uma "verdade histórica" através da interpretação, Freud concluiu que o motor da cura não está relacionado à comunicação de um saber, mas à atualização da materialidade que sustenta a significação (1932, p. 291).

A obra de Lacan também testemunha mudanças em relação à direção do tratamento, e podem-se encontrar diferentes paradigmas que autorizam falar-se em concepções diferentes de tratamento. Pode-se encontrar uma forma de Lacan dirigir o tratamento, correlacionada ao desenvolvimento do registro do Imaginário, no texto "Intervenção sobre a transferência", em que Lacan sugere uma concepção do tratamento que pode ser entendido como "reconhecimento do desejo", culminação das "inversões dialéticas" produzidas pelo analista a partir dos diversos "desenvolvimentos da verdade" (1966, p. 214).

Um segundo momento, pode ser correlacionado à inclusão do Simbólico, em que o objetivo do tratamento seria comunicar ao paciente um significante que pudesse enunciar sua última verdade. Isto seria possível devido ao fato de o analista poder buscar, na sincronia da cadeia significante, a diacronia que o determina. Bus- 
ca justificada pela estrutura da linguagem, em que o rastreamento das metonímias elucida as metáforas, indicando sua causa material nas letras que as condicionam.

Pode-se ainda sugerir um terceiro período na obra de Lacan em que a determinação do sentido passa a ser condicionada pela idéia de um "significante assemântico", produzindo uma submissão do sentido ao gozo. Porém, nesses vários movimentos da prática analítica, permanece constante a referência à transferência, a ponto de a orientação lacaniana ser vista como clínica da transferência, ou clínica do significante, ou ainda clínica do Outro.

Lacan retomou o conceito de transferência de Freud articulando seus diferentes desenvolvimentos, esquematizando-os em três momentos: transferência como repetição, transferência como resistência, e finalmente articulando-a com a sugestão. Sem abandonar nenhuma destas três perspectivas, Lacan procurou definir uma essência da transferência e buscou um eixo que possibilitasse articular essas várias formalizações numa só, encontrando-o na estrutura da situação analítica, pensando a transferência como uma conseqüência imediata da associação livre. Ou seja, o analisante, ao associar, o faz para alguém, pondo o analista como um ouvinte privilegiado da busca do analisando da verdade sobre ele mesmo nos limites das suas palavras. Limite posto no analista, enquanto encarna um ouvinte especial, que decide da verdadeira significação das suas palavras.

Para Lacan existe transferência devido ao fato de o paciente associar livremente, e é na submissão do analisante à regra fundamental, à regra de dizer tudo a um outro, em que se pode conectar o inconsciente, pensado como um saber, a um sujeito. Desde este prisma, a transferência é relação com o saber. Este saber porém é, na situação analítica, atribuído ao ouvinte, "lugar" do analista, e não necessariamente à sua pessoa. Se a transferência é de amor, o marcante é que se trata de amor a qualquer um que esteja na posição de analista. Este "qualquer um", peculiar da situação analítica, é o conceito de Outro. Por isso a clínica lacaniana é a clínica do Outro, ou clínica da transferência, constituindo a linguagem um terceiro como referência comum para os dois.

A invenção de Freud é a invenção do analista como Outro. $O$ analisante, pelo fato de aceitar a regra fundamental, que o põe na posição de não saber o que diz, cai na dependência desse Outro. No entanto, não se trata de uma dependência real. Trata-se da dependência da relação desse sujeito com o saber. Saber este, que é o que se procura numa psicanálise. A esse elemento que define a essência, o motor da transferência, a essa relação epistêmica, Lacan chamou Sujeito Suposto Saber. 
Devido a haver diferentes modalidades de saber compartidas socialmente nos diferentes momentos históricos, pode-se falar em diferentes modos de subjetivação nos diferentes momentos da história, pois o Sujeito estabelece diferentes modos de relação com o Outro no decurso da história.

\section{MODERNIDADE, PÓS- MODERNIDADE, SUJEITO, SABER E TRANSFERÊNCIA}

Decorrente de a clínica analítica ser clínica da transferencia e esta estar relacionada com o saber, para acompanhar o momento atual da psicanálise, haveria que situá-la diante do paradigma do que é considerado como pós-moderno. Termo que aponta para uma superação da "modernidade", categoria transformada em questão somente recentemente, pois, segundo Foucault, foi apenas com Kant que se introduziu a pergunta sobre a "atualidade", fazendo do tempo presente um acontecimento a ser formalizado (Fonseca, 1995). O "moderno" como questão cristalizou-se com Max Weber e Habermas, os primeiros a usar a palavra modernização como terminus, associando-a à formação de capital e ao estabelecimento de poderes políticos centralizados.

Lacan refere-se à modernidade falando da particularização da ciência moderna, de um pensamento 
moderno, de admitir uma era moderna, o que mostra preocupação em estabelecer uma relação do momento histórico com o Sujeito. No Seminário III, Lacan sugere que um dos temas que caracterizam o pensamento moderno é a idéia de um personagem vivendo só em uma ilha deserta, e menciona Robinson Crusoe. Lacan (1968a) retoma esta referência no seminário "De um Outro a um outro", sugerindo que essa idéia representa o começo da era moderna, pois seria fundamental para o homem moderno afirmar sua independência e autonomia em relação a todo amo e Deus. Enfatizando esta posição, em "Ciência e verdade", Lacan utilizou a expressão "um certo momento do sujeito" e, ainda referindo-se ao sujeito, "um momento historicamente definido", e, ainda em relação ao sujeito, "um momento historicamente inaugural" (1966, p. 869).

A razão da possibilidade de temporalizar o sujeito está na afirmação de Lacan de que o sujeito está definido em relação ao saber. Como o saber muda, o sujeito também muda, causando o surgimento de novas maneiras de subjetivação em função da nova relação deste com o saber. Para Lacan, o aparecimento do sujeito moderno localiza-se historicamente com a publicação das Meditaçôes metafísicas de Descartes, que, pela operação do Cogito, teria produzido o sujeito moderno. O Sujeito Cartesiano é o pressuposto $\mathrm{da}$ noção de inconsciente, pois a psicanálise, tal qual Descartes, parte do fundamento da existência de um sujeito da certeza, ou seja, o Sujeito pode ter certeza de si, desde que se possam destacar no seu discurso dúvidas que aparecem como reveladoras de um sujeito dividido. O lugar do "Eu penso" é para Freud independente do "Eu sou". Caberia então a pergunta: há um sujeito que seja atual, e que fosse produzido por um saber novo compartido nos dias de hoje?

No Dicionário Aurélio, o termo "sujeito" aparece definido como: "ser individual, real, que se considera como tendo qualidades ou praticado ações". No Dicionário de filosofia de Oxford, o mesmo termo aparece como sinônimo de Eu. No Vocabulário técnico e crítico de filosofia de A. Lalande, aparece definido desde a lógica, a metafísica, a psicologia, a sociologia, o direito e a filosofia. O uso do termo "sujeito" varia também dentro da filosofia: para Heidegger, "sujeito" é uma categoria da filosofia que se deve desconstruir; para Marx, a história é um processo sem sujeito, portanto "sujeito" seria uma categoria da ideologia; a fenomenologia, por sua vez, identifica o sujeito à consciência.

Pensando desde a psicanálise, constata-se que Freud, embora não tenha utilizado o termo "sujeito", abordou-o com outra terminologia, podendo-se dizer que Freud usou o termo "Das Ich" para se referir ao sujeito da experiência. Segundo L. Boyer, o sujeito, em Melanie Klein, pode equivaler "aos modos de atribuir significado à experiência (as posições)" (Ogden, 1996). Em Lacan, o termo "sujeito" está presente desde seus primeiros escritos, e seu uso parece equivaler a "ser humano"; de- 
pois Lacan diferencia o sujeito da lógica do sujeito gramatical, assim como esses sujeitos são definidos por serem opostos ao objeto. Lacan também diferencia o sujeito noético, gramatical, do sujeito anônimo e ambos do Sujeito, cuja singularidade se define por um ato de afirmação. É este Sujeito, entendido como o que se define por um ato de afirmação, que Lacan diferencia do Eu. O Eu é entendido como a sensação de um corpo unificado, e, na teoria do estádio do espelho, encontra-se produzido desde a imagem do outro.

Lacan, no Seminário III, diz: "Aristóteles observava que não convém dizer que o homem pensa, mas que ele pensa com sua alma. Da mesma maneira, eu digo que o Sujeito se fala com o seu Eu" (1956, p. 23). À diferença do Eu, que para Lacan é construído desde a imagem do outro, o Sujeito decorre do Outro, que é referência à linguagem enquanto efeito da ordem simbólica. Por isso o Sujeito é conseqüência do significante, e está regido pelas leis do Simbólico. Para Lacan, portanto, a causa do Sujeito é a estrutura do significante. O Sujeito não é uma sensação consciente, uma ilusão produzida pelo Eu, senão que é insconsciente, e por isso não é o agente da fala, suporte da estrutura, mas descentrado, acéfalo, dividido, evanescente. O Sujeito na psicanálise é explicitamente diferente da consciência, portanto é um Sujeito não fenomenológico. Não é uma categoria normativa, ele é uma categoria clíni$c a$, e não remete a uma totalidade.

Levando-se em consideração a articulação existente entre Sujeito e 
história, para alguns autores, o sujeito pós-moderno seria caracterizado por não ser mais um Sujeito que tenha um saber compartido socialmente, seria um sujeito sem paradigmas de consenso, seria o sujeito decorrente da mudança dos costumes sexuais, das mudanças ideológicas, seria o Sujeito que sofre da ausência de ideais préestabelecidos. Seria esse Sujeito pós-moderno conseqüência do novo materialismo introduzido pela neurobiologia atual, que se caracteriza pela ausência de um Sujeito desejante, ou seria esse Sujeito pós-moderno a consequêencia do "declínio" da funçāo paterna?

Como o Sujeito decorre do saber, e como a pós-modernidade caracteriza-se pela ausência de paradigmas estabelecidos e pelo questionamento do saber (teoria do caos, teoria das catástrofes, nova ciência etc.), cabe a pergunta: ao questionar sua relação com o saber, qual transferência estabelece o Sujeito pós-moderno?

\section{PSICANÁLISE E SUJEITO PÓS-MODERNO: RESPOSTAS DO REAL}

$\mathrm{Na}$ evolução do ensino de Lacan, pode-se falar em um primeiro momento, correlacionado à demonstração da determinação do sentido, entendido como efeito do funcionamento da linguagem formalizada com a noções de metáfora-metonímia, "point-de-capiton", significação fálica, e Nome-do-Pai. Nesse modelo da prática da psicanálise, o analista ocupa o lugar do Outro, e na interpretação aponta a um significante que possa dizer toda a verdade do sujeito.

A segunda clínica de Lacan seria uma mudança de axioma que se opera em 1970, quando, no seminário “...Ou Pire”, Lacan (s.d.) enuncia "I'l y a de I'Un", problemática que condiciona o interesse pelo nó borromeano.

O que quẹr dizer o acento posto no Um? Quer dizer que o Sujeito não procede da cadeia. Por isto Lacan passa a enfatizar a noção de signo, pensado como uma ocorrência do Um, ou seja, como um significante sem cadeia. Pode-se com isso entender o deslocamento do DOIS, ou do múltiplo da cadeia, para o UM, pois o que distingue um signo de um significante é que o signo não tem uma estrutura binária.

Pode-se também articular essa mudança de axioma com a introdução do conceito de gozo. A introdução do gozo modifica o valor dado à metonímia (ver Radiofonia), fazendo com que houvesse uma mudança do acento antes posto sobre a metáfora, deslocando-o para a metonímia. (clínica da conexão). 
A partir daí se pode opor então a trilogia significante, significado e efeito de significação a signo, sentido e efeito de gozo. Estas mudanças implicam uma nova definição de inconsciente, que passa a ser entendido como um saber cifrado, que aloja um gozo, um saber escrito. Haveria então uma mudança da ênfase do entendimento do inconsciente de um "querer dizer", que seria o paradigma da primeira clínica, para um "querer gozar", paradigma da segunda clínica.

Outra consequência dessa mudança de paradigma: uma definição renovada de linguagem, não mais como meio de comunicação, mas como aparelho de gozo. Nesse momento, Lacan define o inconsciente como um saber fazer com a alingua. Ou seja, há uma substituição da linguagem por alingua, de lingüística por linguisteria, de desejo (querer dizer) por gozo (querer gozar). Cito Lacan: "Se eu disse que a linguagem é como o que o inconsciente está estruturado, é certamente porque a linguagem, em primeiro lugar, não existe. A linguagem é isso que se trata de saber a respeito da função de alingua..." (1972a, pp. 126-7).

Daí que o eixo dessa segunda clínica de Lacan poderia ser a separação do sentido e do Real. E seria esta antinomia entre Real e sentido que fez com que no último ensino de Lacan a questão do sintoma tenha se tornado uma prioridade, pois se o real exclui completamente o sentido o sintoma é uma exceção (Joyce).

As conseqüências teóricas dessa mudança de paradigma é que se há $U m$, se a linguagem é condicionada pela alingua, se não há comunicação, no nível da alingua, então todos monologamos. Também com o conceito de apalavra se termina a referência à comunicação, não há diálogo, há autismo, logo não há Outro. Conseqüência clínica: se não se não há diálogo, isso implica reformular-se a prática da interpretação.

Em Televisão, Lacan opõe o significante não mais ao significado, mas a partir daí ao signo, constituindo com isso um abandono do par metáfora/metonímia e uma ressignificação do conceito de linguagem (1972c). Com isto, o que antes, com o binarismo saussuriano, dava conta dos efeitos de significação, teria sido substituído pelo par signo/sentido, que daria conta da produção de gozo. Também a referência ao gozo reintroduz de outra maneira a referência à letra e sua articulação com a escritura. Por isto, a questão de qual é o sentido do sentido é respondida por meio do gozo e, a partir daí, a clínica analítica será pensada no que vai além de um querer dizer, que seria a vontade de gozo. A clínica analítica deixa de ser concebida como um diálogo, não há conversação, e, por isto, o Outro não existe.

O que resta é o laço social (os discursos), que é o único que pode pôr limite ao P.D.D. (pas de dialogue) (Miller, 1996a). Em 
termos da direção do tratamento impõe-se então uma interpretação que não aponta para o sentido, e isto constituiria a "época lacaniana da psicanálise", que é uma orientação para o Real.

Para dar conta dessa outra interpretação, Lacan passa a indagar a relação entre o sentido e o gozo com os termos usados por Frege, Sinn e Bedeutung, passando então a pensá-los como o que poderia formalizar a separação do Real e do sentido (o que leva a reconsiderar o Nome-do-Pai a partir do pai do nome).

Poder-se-ia também inferir que o gozo poderia ser considerado como a abordagem lacaniana do ponto de vista econômico em Lacan, e haveria igualmente uma retomada do conceito de defesa relativizando o conceito de recalque, justificando desta maneira a proposta de uma "forclusão generalizada" como o paradigma do que funda a falta.

Portanto, a segunda clínica incide na direção do tratamento principalmente na concepção da "interpretação como sinônimo de inconsciente", como tradução do sentido simbolizado pelas suas produções, e articula o inconsciente como linguagem com a interpretação como metalinguagem, pois a interpretação, visando uma "palavra esclarecedora", forneceria o sentido oculto do inconsciente, fosse um sonho, um sintoma, um ato falho (Miller, 1996c). Desta maneira, este modelo anterior $\mathrm{da}$ interpretação apontaria sempre e unicamente para um deciframento que, devido à estrutura da linguagem, seria sempre infinito.
Já a interpretação proposta no último período do ensino de Lacan não seria mais concebida como uma mensagem a ser decifrada, mas um ato que incidiria no gozo produzido pelo ciframento. Neste novo modelo, a direção de um tratamento indicaria que, na era chamada de "pós-interpretativa", o analista não deveria se orientar unicamente pelo sintoma e seus sentidos, mas pelo efeito da incidência do Real no significante, por meio do que Lacan chamou de "Sinthome" (Miller, 1996b).

Essa intervenção do analista não visaria um deciframento definido pelo estabelecimento de um novo sentido, mas apontaria para uma atualização de seu suporte material, chamado por Lacan de "letra". Isto fez com que a prática da psicanálise fosse concebida como uma leitura de uma "escrita" que seria constitutiva do inconsciente. Esta nova interpretação recebeu uma formalização decorrente de o significante ser condicionado à "letra", que seria sua causa material. A proposta de uma causa material para o significante está presente no ensino de Lacan desde seu texto, de 1957, "Instância da letra no inconsciente, ou a razão depois de Freud" (1966, p. 496), e foi modificada em "Lituraterre" (1972b) e depois em "Mais, ainda" (1972a), quando foi equiparada por Lacan ao conceito de "gérmen".

Lacan, em 1960, no escrito "Posição do inconsciente" propôs um outro modelo para a interpretação, que visava dar conta de uma interpretação que não apontasse para o sentido cifrado e que, por isto mes- 
mo, não seria a enunciação de um significante a mais que, acrescentado à cadeia, esclareceria os outros, mas sugeria esta outra interpretação como um ato que incidiria no "intervalo" da cadeia significante (1966, p. 843).

Essa nova interpretação analítica foi introduzida por Lacan correlacionada a uma reformulação da noção de inconsciente feita por ele com a introdução das operações da causação do sujeito, a "alienação" e a "separação". No modelo anterior a compreensão do dispositivo psicanalítico era pensada de acordo com as propriedades do "Registro do Simbólico", pelas quais o analisando, via transferência, punha o analista no lugar de "Mestre do Sentido". Isto faria com que o analista dissesse uma verdade sobre o dito do analisando, subvertendo com isso o seu desejo. No momento posterior do ensino de Lacan, o analista deixou de ocupar exclusivamente o lugar de "Outro", que é o lugar em que as significações adquirem valor de verdade, para situar-se numa posição equivalente à de "objeto causa do desejo", ou "objeto pequeno a".

$O$ analista, atuando nessa posição, produziu uma reformulação da teorização do Registro do Real que, ressignificado, passou a ser visto como determinando o Registro do Simbólico. Com isso, houve uma reformulação da categoria de Desejo, que passou a se contrapor a Gozo. Da mesma maneira que o conceito d e Significante ficou repartido em dois "litorais", que seria o sentido e a Letra. O gozo, como face de letra do significante, responderia a sua fixidez, que é seu modo de existência fora do sentido. Esta fixidez, essa existência fora do Simbólico, leva a uma reflexão sobre a "materialidade" que condiciona o significante e também requer o estabelecimento de sua relação com a noção de "Substância", que foi apresentada por Lacan como "substância gozante" (Lacan, 1972a).

Dever-se-á ainda relacionar a "letra" com o conceito freudiano de "inscrição psíquica”, e também com o de "traço unário", além de estabelecer as suas articulações com o "Significante índice um", e examinar as relações desses conceitos com a noção de Real.

Como conseqüência desse novo modelo da interpretação psicanalítica, podem-se questionar as interpretaçōes feitas por Freud da cultura, em que Freud havia tomado a neurose como parâmetro. Para Freud, os produtos culturais (entre eles, a arte e literatura) foram pensados como equivalentes às formações do inconsciente, e sua interpretação seguiu o mesmo modelo da interpretação dos sonhos, em que o conteúdo manifesto que os compõe foi tomado como semelhante aos fatos culturais, e ambos, sonho e cultura, foram explicados como o resultado final de processos inconscientes latentes, decorrentes dos mecanismos de 


\section{Fundamentos}

deslocamento e condensação, causados pelo recalque.

Mas, se a interpretação do recalcado, apresentada como a revelação de seu sentido oculto, encontra-se subvertida dentro da prática de orientação lacaniana, então haveria que se pensar em um novo modelo para a interpretação da cultura?

\section{A INTERPRETAÇÃO ENTRE O IDEAL E O SINTOMA}

Se, para Freud, a interpretação apontava unicamente à enunciação do desejo inconsciente, Lacan por sua vez desenvolveu um outro modelo para a interpretação, em que ela não mais apontaria para as formações do inconsciente entendidas unicamente como realizações de desejos.

Por meio da formalização do "objeto pequeno a" como objeto causa do desejo, Lacan produziu um uso da interpretação que não comunicaria o sentido oculto do sintoma, ou da produção cultural, mas uma interpretação que incidiria sobre a causação material do Sujeito.

Dessa maneira, a partir de 1968, no Seminário XVII, encontra-se em Lacan (1968b) a idéia de que o que constituiria os discursos seria o efeito da circulação deste objeto causa, que, por ser objeto, é diferente do significante e, portanto, fora do sentido. $O$ vínculo entre os discursos e a cultura poderia ser sugerido devido ao fato de que o objeto peque- 
no a, ou objeto causa do desejo, foi também proposto por Lacan (1968a) no Seminário XVIII, "De um Outro a um outro", como objeto mais-gozar, numa relação do mesmo com a noção de "maisvalia”, introduzida por Marx.

Da mesma maneira, nas poucas referências que Lacan fez à arte, esta foi pensada diferentemente de Freud, que a relacionou ao desejo e articulou-a à idéia de sublimação. Para Lacan, a obra de arte organiza-se em torno de um vazio e, na sua interpretação, sem darthe um sentido, entendeu-a como articulada ao objeto causa do desejo, fundamento do Sujeito.

Assim, uma interpretação da cultura que leve em conta esses fatores ele não a poderia articular, como o fez Freud, em função de satisfações substitutivas, mas o faria por meio das trocas objetais, condicionadas pelos laços sociais que constituem os discursos.

Seria então a proposta dos "quatro discursos", introduzida por Lacan (1968b) no Seminário "O avesso da psicanálise”, uma nova maneira de pensar a cultura? E seria o quinto discurso, o discurso do capitalista, a leitura psicanalítica da cultura atual?

A formalização de uma interpretação que operaria "fora do sentido" deu-se ao longo de todo o ensino de Lacan. A nova interpretação analítica, segundo Lacan, seria aquela que alcança a resposta do Real. Por isso, a interpretação não seria formulada em termos da significação que ela produziria, mas em função dos significantes pelos quais a significação foi formulada, isto porque uma mensagem, mesmo decifrada, permanece um enigma, na medida em que a relação do sujeito e sua representação significante só pode ser relacionada, em última instância, a sua causação material (1973, pp. 5-52).

Daí a sugestão de Lacan de que o que deve ser interpretado não são os ditos de um paciente, mas sim o seu dizer. Esta proposta foi equacionada por Lacan em termos de que a interpretação seria o que faz passar um dito do "modal" para o "apofântico" (1973). O modal seria o que inscreve a posição ou a atitude do sujeito com relação ao enunciado pelo verbo. $O$ apofântico seria o dizer particular, que oscila entre a revelação e a asserção. Estes efeitos seriam produzidos pela pontuação, pelo corte, pela alusão, pelo equívoco, pela citação, pelo enigma.

Para Lacan, a interpretação seria um dizer essencialmente silencioso, a qual apontaria para o fato de que um significante esconde outro significante, ou que uma significação esconde outra significação, procurando, no entanto, o que de Real condiciona este efeito de significação, revelando desta maneira a consistência lógica do objeto, que, em última análise, seria o impossível de dizer.

Para esclarecer a maneira pela qual opera a interpretação psicanalítica, Lacan referiu-se à lógica, por meio do pensamento de Fre- 


\section{Fundamentos}

ge, que estabeleceu uma diferença entre sentido ( $\operatorname{Sin} n$ ) e significação (Bedeutung). Frege, oito anos antes de Freud publicar $A$ interpretação dos sonhos, publicou um artigo com o título "Über Sinn und Bedeutung", traduzido como "Sobre o sentido e a significação", com o propósito de separar o conteúdo, a conotação (o Sinn), da denotação (a Bedeutung). Lacan referiu-se a esse artigo na conferência pronunciada em Genebra, em 1976, publicada com o título "Sobre o sintoma", onde assinalou que o Sinn seria o efeito de sentido determinado a partir do efeito de significado. Já a Bedeutung seria, para Lacan, o efeito que concerne à relação do significante com o Real.

Esta distinção entre Sinn e Bedeutung serviu para demonstrar o caminho que vai do sentido a algo além do sentido, conotando com isto um parentesco entre a verdade $e$ o gozo. O sentido, Sinn, seria o gozo que se situa entre o Imaginário e o Simbólico, já a significação, a Bedeutung, apontaria para o gozo no Real, que condicionaria os efeitos do Simbólico.

\section{REFERENCIAS BIBLIOGRÁFICAS}

Fonseca, M. (1995). Michel Foucalult e a constituição do sujeito. São Paulo, SP: Educ.

Freud, S. (1895). Estudos sobre a histeria. In Edição standard brasileira das obras completas de Sigmund Freud (J. Salomão, trad.) (Vol. 2, p. 43). Rio de Janeiro, RJ: Imago, 1972.
(1920). Além do princípio do prazer. In Edição standard brasileira das obras completas de Sigmund Freud (J. Salomão, trad.) (Vol. 18, p.17). Rio de Janeiro, RJ: Imago, 1972.

(1932). Construçōes em análise. In Edição standard brasileira das obras completas de Sigmund Freud (J. Salomāo, trad.) (Vol. 23, p. 291). Rio de Janeiro, RJ: Imago, 1972.

Lacan, J. (1956). O seminário. Livro III, As psicoses. Rio de Janeiro, RJ: Jorge Zahar, 1985.

(1966). Escritos. Rio de Janeiro, RJ: Jorge Zahar, 1998.

(1968a). De um Outro a um outro. Seminário inédito.

(1968b). O seminário. Livro XVII, O avesso da psicanálise. Rio de Janeiro, RJ: Jorge Zahar, 1992.

(1972a). Le séminaire. Livre $X X$, Encore. Paris: Éditions du Seuil, 1970 [No Brasil: O seminário. Livro $\mathrm{XX}$, Mais, ainda. Rio de Janeiro, RJ: Jorge Zahar, 1982].

(1972b). Lituraterre. Ornicar?, no 41, 1987.

(1972c). Televisão. Rio de Janeiro, RJ: Jorge Zahar, 1993.

(1973). L'étourdit. Scilicet, ne 4, pp. $5-52$.

(s.d.). “...Ou Pire”. Seminário inédito.

Miller, J.-A. (1996a). Le monologue de la parole. Curso "Le fuite de sens" (7 aula). La Cause Freudienne, no 34.

(1996b) A interpretação pelo avesso. Opção Lacaniana, $\mathrm{n}^{\circ} 15$.

(1996c). El inconsciente interprete. Freudiana, $\mathrm{n}^{\circ} 14$.

Ogden, T. (1996). Os sujeitos da psicanálise. Sào Paulo, SP: Casa do Psicólogo, 1996.

Recebido em 05/06/2000. 